\title{
Síndrome nefrótica em cão associada à Babesia canis
}

\author{
Nephrotic syndrome in dog associated Babesia canis \\ Liziane Ferraresi Holanda Cavalcante', Elisa Barp Neuwald', Fabíola Peixoto da Silva Mello², Luciana \\ de Almeida Lacerda ${ }^{3}$, Simone Tostes de Oliveira ${ }^{4}$, Janete Maria Volpato Marques ${ }^{1} \&$ Alan Gomes Pöppl ${ }^{5}$
}

\section{RESUMO}

A Síndrome Nefrótica (SN) é uma consequiência da doença glomerular renal e se caracteriza por proteinúria, hipoalbuminemia, hipercolesterolemia, hiperlipemia e edema; podendo estar ou não associada a distúrbios infecciosos. Este relato descreve o caso de um cão, Fila Brasileiro, com histórico de fraqueza, edema facial e dos membros, apatia e desidratação. Os exames complementares revelaram infecção por Babesia canis, insuficiência renal crônica, hipertensão arterial e os sinais já citados da SN.

Descritores: doença glomerular, babesiose, cão, proteinúria.

\section{ABSTRACT}

Nephrotic Syndrome is a consequence of renal glomerular disease and is characterized by proteinuria, hypoalbuminemia, hypercholesterolemia, hyperlipiemia and edema; could be or not associated to infeccious disturbances. This story reports a case of a dog, Fila brasileiro, with history of weakness, face and limb edema, apathy and dehydration. Selection examinations reveal Babesia canis infection, renal chronic failure, arterial hypertension and signs once cited of SN.

Key words: glomerular disease, babesiosis, dog, proteinuria. 


\section{INTRODUÇÃO}

A forma clássica da $\mathrm{SN}$ se caracteriza por proteinúria, hipoalbuminemia, hipercolesterolemia, hiperlipemia e ascite ou edema [1,2,4,5,7,16-18,20,21]. A principal causa de SN nos cães é a glomerulonefrite imunomediada, causada pela presença de imuno-complexos nas paredes dos capilares glomerulares [4,5,7,11,16-18, 20,21].

Nela, o edema e/ou ascite constituem a queixa mais comum e ocasionalmente podem estar associados a sinais clínicos de distúrbios infecciosos [5,7,16,21]. Isso depende da gravidade e duração da perda urinária de proteína, bem como da presença ou ausência de insuficiência renal e complicações, sendo o tromboembolismo, a hipercoagulabilidade e a hipertensão as mais freqüentes [1,7-9,16].

A babesiose canina é uma doença infecciosa causada por um hematozoário do gênero Babesia. Os sinais clínicos dependem da espécie, imunidade do hospedeiro, idade e doenças concomitantes. Apesar da anemia hemolítica auto-imune ser a característica principal, variações severas da doença e complicações podem ocorrer, tais como: insuficiência renal aguda, sinais neurológicos, coagulopatias, hepatopatia, hemoconcentração, hipotensão e síndrome da angústia respiratória $[3,6,10,12]$.

A glomerulonefrite tem sido descrita em associação a babesiose canina. Esta pode ser explicada por dois mecanismos: a anemia hemolítica severa resulta em potencial lesão tubular, nefrite intersticial e glomerulopatia; e o mecanismo auto-imune resulta em depósito e imuno-complexos nos glomérulos, levando por fim, à glomerulonefrite, podendo causar os sinais já descritos de SN [3].

O objetivo deste relato é descrever um caso de síndrome nefrótica associada à babesiose em um canino.

\section{RELATO DE CASO}

Um cão, Fila Brasileiro, 8 anos de idade, pesando $56 \mathrm{~kg}$, foi atendido no Hospital de Clínicas Veterinárias da Universidade Federal do Rio Grande do Sul (HCV-UFRGS), com histórico de tremores, fraqueza e colapso após esforço, há seis meses. Nas duas semanas anteriores a consulta, o animal começou a apresentar edema dos membros e depois da face. Levado anteriormente a um veterinário foi tratado como cardiopata, porém não apresentou melhora clínica.

Ao exame clínico o animal apresentava temperatura retal de $37,9^{\circ} \mathrm{C}$, mucosas pálidas, tempo de preenchimento capilar de 3 segundos, intensa dispnéia, desidratação de aproximadamente $10 \%$, e apatia severa. À auscultação cardio-respiratória observou-se abafamento das bulhas cardíacas e presença de estertores pulmonares. $\mathrm{O}$ animal apresentava acentuado edema de face, membros anteriores e pescoço, mas com menor intensidade nos membros posteriores.

Foi instituído tratamento sintomático com fluidoterapia e diurético e o animal foi submetido a exames complementares.

Imediatamente após a coleta de sangue foi observada auto-aglutinação macroscópica do sangue in vitro. O hemograma revelou uma anemia normocítica normocrômica, presença de policromasia e anisocitose, plasma com microcoágulos e hemácias aglutinadas. O leucograma revelou neutrofilia com desvio à esquerda regenerativo. A pesquisa para hemocitozoário foi positiva para Babesia canis. Os exames bioquímicos revelaram hipoalbuminemia (26-33g/l), aumento sérico nos valores de proteínas totais $(60 \mathrm{a}$ $80 \mathrm{~g} / \mathrm{l})$, creatinina $(0,5-1,8 \mathrm{mg} / \mathrm{dl})$, fosfatase alcalina $(<156 \mathrm{u} / \mathrm{l})$ e colesterol $(135-270 \mathrm{~g} / \mathrm{l})$. A urinálise demonstrou densidade urinária diminuída $(1,012)$, proteinúria acentuada $(>300 \mathrm{mg} / \mathrm{dl})$, hematúria, piúria, presença de células renais e vesicais, cilindros granulosos e celulares e presença de cristais de urato amorfo.

A radiografia torácica demonstrou cardiomegalia, e aumento de radiopacidades em campos pulmonares, com sinais de congestão. $\mathrm{O}$ eletrocardiograma evidenciou taquicardia sinusal, enquanto que a ultrasonografia evidenciou esplenomegalia leve, hepatomegalia e rins apresentando hiperecogenicidade e aumento de área de cortical, associado à diminuição de área medular, com pouca definição de cálices, sugerindo quadro de insuficiência renal crônica.

A mensuração da pressão arterial foi realizada utilizando aparelho de Doppler vascular (DV 610 Medmega), demonstrando pressão arterial sistólica (PAS) de $230 \mathrm{mmHg}$, indicando hipertensão arterial.

O tratamento foi realizado com fluidoterapia (solução de ringer lactato), antimicrobiano (enrofloxacina $-5 \mathrm{mg} / \mathrm{kg}$ BID), inibidor de enzima conversora da angiotensina (maleato de enalapril $-0,5 \mathrm{mg} / \mathrm{kg}$ BID), diurético (furosemida $-2 \mathrm{mg} / \mathrm{kg}$ TID), corticóide (prednisona - $1 \mathrm{mg} / \mathrm{kg}$ SID), anti-trombótico (ácido-acetilsalicílico - 5mg/kg SID) e antiparasitário (dipripionato de imidocarb $-4 \mathrm{mg} / \mathrm{kg}$ em dose única).

$\mathrm{O}$ animal voltou a se alimentar e houve regressão do edema, sendo liberado após 10 dias de inter- 
nação para continuar tratamento em casa. O cão não retornou para revisão e foi a óbito 3 semanas depois, não sendo realizada necropsia.

\section{DISCUSSÃO}

No presente relato foi observado a combinação de: proteinúria significativa, hipoalbunemia, edema, hipercolesterolemia e hipertensão sistêmica, características da SN. As alterações detectadas na urinálise, na creatinina sérica e nos achados ultra-sonográficos indicam alteração renal grave, a qual foi responsável pela hipoalbunemia, permitindo assim o escape dos fluidos do compartimento vascular para o espaço intersticial, iniciando o edema. Além disso, a redução do volume plasmático e do débito cardíaco estimula o aumento da atividade do sistema renina-angiotensinaaldosterona, causando retenção de água e sal, com formação adicional de edema.

A hipertensão se instala resultante da combinação de retenção de sódio, fibrose dos capilares e arteríolas glomerulares, diminuição renal da produção de vasodilatadores, aumento da responsividade a mecanismos pressores normais e ativação do sistema renina angiotensina [2,7,16-18,21]. A utilização de maleato de enalapril e furosemida visou controlar o edema e a hipertensão sistêmica que o animal em questão apresentava.

O desenvolvimento das alterações renais pode ter sido decorrente de deposição de imuno-complexos devido à presença do hemoparasita. Dessa forma, além de levar à destruição de hemácias por anemia hemolítica, pode ter gerado lesão renal grave. Sabe-se que animais com babesiose apresentam intensa reação inflamatória, caracterizada por proteinúria, hipoalbuminemia, com conseqüente deposição de imunocomplexos nos túbulos renais [3,12-14]. Na tentativa de se reduzir a destruição de hemácias e a formação de imuno-complexos, optou-se pela utilização da prednisona em doses imunossupressoras; e o dipripionato de imidocarb, droga hemoparasiticida, para o tratamento da babesiose $[2,10,12,15,16,19,20]$.

A hipercolesterolemia e hiperlipidemia resultam da combinação na redução do catabolismo e aumento da síntese hepática de proteínas e lipoproteínas, levando ao acúmulo de lipoproteínas ricas em colesterol, enquanto as proteínas de peso molecular baixo (albumina e antitrombina III) são perdidas na urina. Nos pacientes nefróticos, como neste caso, as concentrações plasmáticas de albumina são inversamente correlacionadas com as concentrações de colesterol. Por isso, uma dieta balanceada com fonte protéica de alta qualidade é essencial em cães com proteinúria severa $[3,4,7,16,17]$.

Trombose é uma complicação comum da síndrome nefrótica, secundária a várias anormalidades no sistema de coagulação, tais como: elevação do fibrinogênio e fatores V e VIII, deficiência de antitrombina III (devido à perda urinária), hipersensibilidade plaquetária e alteração na fibrinólise, podendo ainda estar complicada pelas alterações hemostáticas provocadas pela presença da Babesia canis (dano endotelial e aumento das proteínas de fase aguda devido á hemólise; e interação das células parasitadas com as células endoteliais), culminando em tromboembolismo pulmonar. A terapia anticoagulante preventiva é indicada nesses casos, podendo utilizar-se drogas como aspirina, heparina ou derivados cumarínicos [1,4,6-9,12,16,21]. Neste caso, isso pôde ser observado pela auto-aglutinação macroscópica do sangue in vitro logo após a coleta, além de intensa dispnéia apresentada pelo animal no momento da consulta. Optou-se pelo ácidoacetilsalicílico pela facilidade de administração.

Pacientes que sofrem de síndrome nefrótica estão bastante susceptíveis a desenvolver infecções bacterianas, que podem ser atribuídas à perda renal de gamaglobulinas e à terapia corticosteróide geralmente instituída, sendo aconselhado antibioticoterapia profilática [2]. Neste caso optou-se pela enrofloxacina, que apesar do seu potencial nefrotóxico, possui amplo espectro e fácil administração. Assim, a fluidoterapia neste caso, além de reestabelecer o equilíbrio hidroeletrolítico do animal, manteve adequado fluxo renal diminuindo as chances de nefrotoxicidade.

Enfim, este animal apresentou alterações clínicas e laboratoriais clássicas da síndrome nefrótica, tendo como agente causador a infecção por Babesia canis. Apesar da utilização da terapêutica adequada, o mesmo não resistiu às complicações inerentes à doença.

\section{REFERÊNCIAS}

1 Abdullah R. 1988. Hemostatic Abnormalities in Nephrotic Syndrome. Veterinary Clinics of North America: Small Animal Practice.18: 105-113. 
2 Bush B.M. 1972. A Review of the Treatment of canine Renal Disease. The Veterinary Record. 90: 669-678.

3 Camacho A.T., Guitian F.J., Pallas E., Gestalt J.J., Olmeda S., Goerthert H., Telford III S. \& Spileman A. 2005. Serum Protein Response and renal Failure in Canine Babesia annae Infection. Veterinary Research 36: 713-722.

4 Choi E.W. \& Lee C.W. 2004. Development of Canine Nephrotic Syndrome Model. Journal of Veterinary Medical Science. 66: $169-74$.

5 Forrester S.D. \& Lees G.E. 1998. Nefropatias e Ureteropatias. In: Birchard S.J. \& Sherding R.G. Manual Saunders: Clínica de Pequenos Animais. 1.ed. São Paulo: Roca, pp. 901-925.

6 Gopeghi R.R., Penãlba B., Goicoa A., Espada Y., Fidalgo L.E. \& Espino L. 2006. Clinico-Pathological Findings and Coagulations Disorders in 45 Cases of Canine Babesiosis in Spain. The Veterinary Journal. Disponível em: <http://www.sciencedirect.com>.

7 Grauer G.F. \& Dibartola S.P. 2004. Doença Glomerular. In: Ettinger S.J. \& Feldman E.C. Tratado de Medicina Interna Veterinária. 5.ed. Rio de Janeiro: Guanabara Koogan, pp. 1751-1766.

8 Green R.A. \& Kabel A.L. 1982. Hypercoagulable State in Three Dogs with Nephrotic Syndrome: Role of Acquired Antitrombin III Deficiency. Journal of American Veterinary Medical Association.181: 914-917.

9 Green R.A., Russo E.A., Greene R.T. \& Kabel A.L. 1985. Hypoalmuminemia Realted Platelet Hypersensitivity in Two dogs with Nephrotic Syndrome. Journal of American Veterinary Medical Association.186: 485-488.

10 Jain N.C. 1993. Essentials of Veterinary Hematology. 1.ed. Philadelphia: Lea e Febiger, pp.182.

11 Jeraj K.P., Vernier R.L., Polzin D., Klausner J.K., Osborne C.A., Stevens J.B. \& Michael A.F. 1984. Idiopathic Immune Complex Glomerulonephritis in Dogs with multisystem Involvement. American Journal of Veterinary Research. 45: 1699-1705.

12 Lobetti R. 2000. Canine Babesiosis. In: Day M., Machin A. \& Littlewood J. Manual of Canine and Feline haematology and Transfusion Medicine. 1.ed. England: British Small Animal veterinary Association, pp. 85-91.

13 Lobetti R.G. \& Jacobson L.S. 2001. Renal Involvement in Dogs with Babesiosis. Journal of the South African Veterinary Association. 72: 23-28.

14 Lobetti R.G., Mohr A.J., Dippenaar T. \& Myburgh E. 2000. A Preliminary Study on the Serum Protein Response in Canine Babesiosis. Journal of the South African Veterinary Association. 71: 38-42.

15 Nelson R.W. \& Couto C.G. 2001. Medicina Interna de Pequenos Animais. 2.ed. Rio de Janeiro: guanabara Koogan, pp. 1035-1036.

16 Nelson R.W. \& Couto C.G. 2001. Medicina Interna de Pequenos Animais. 2.ed. Rio de Janeiro: Guanabara Koogan, pp. 480-485.

17 Osborne C.A., Low D.G. \& Finco D.R. 1972. Canine and Feline Urology. 1.ed. Philadelphia: W.B Saunders Company, pp. 228-231.

18 Osborne C.A., Hammer R.F., Resnick J.S., Stevens J.B., Yano B.L. \& Vernier R.L. 1976. Natural Remisson of Nephrotic Syndrome in a Dog with Immune-Complex Glomerular Disease. Journal of American Veterinary Medical Association. 168: 129-137.

19 Quinn P.J., Donnely W.J.C., Carter M. E., Markey B.K.J., Torgerson P.R. \& Breatnach R.M.S. 1997. Microbial and Parasitic Disease of the Dog and Cat. Britain: W. B Saunders, pp. 243-244.

20 Rijnberk A. 1966. A Nephrotic Syndrome in the Dog Treated with Prednisone. Zentralblatt für Veterinärmedizin. Reihe A. 13: $102-110$.

21 Tilley L.P. \& Smith J.R. 2003. ConsultaVeterinária em 5 Minutos: Espécies Canina e Felina. 2.ed. Manole, pp. $128-129$. 